\title{
Construction of a recombinant adeno-associated virus (rAAV) vector expressing murine interleukin-12 (IL-12)
}

\author{
Devchand Paul, ${ }^{1}$ Muzaffar H. Qazilbash, ${ }^{1}$ Kaimei Song, ${ }^{1}$ Hui Xu, ${ }^{2}$ Birandra K. Sinha, ${ }^{1}$ \\ Johnson Liu, ${ }^{3}$ and Kenneth H. Cowan ${ }^{1}$ \\ ${ }^{1}$ Medicine Branch, National Cancer Institute, ${ }^{2}$ National Eye Institute, and ${ }^{3}$ Hematology Branch, National \\ Heart, Lung, and Blood Institute, National Institutes of Health, Bethesda, Maryland 20892.
}

IL-12 is a heterodimeric cytokine that is known to induce tumor regression and long-term antitumor immunity. Recombinant adeno-associated virus (rAAV) vectors are advantageous for gene therapy in that they lack pathogenicity in humans, infect dividing as well as nondividing cells, and show a broad range of infectivity. We constructed an rAAV vector expressing interleukin-12 (IL-12) for cancer immunotherapy studies in a mouse model by inserting murine IL-12 (mIL-12) p35 and p40 cDNAs into the plasmid pRep4 and inserting the encephalomyocarditis virus internal ribosomal entry site between the p35 and p40 cDNAs. The mIL-12 expression cassette containing the Rous sarcoma virus promoter and a simian virus 40 polyadenylation signal was subcloned into the AAV plasmid p008Sub/NeoR, which contains two AAV inverted terminal repeat sequences and the NeoR gene driven by the thymidine kinase promoter. rAAV virions $\left(10^{4}\right.$ infectious particles $\left./ \mathrm{ml}\right)$ were generated by cotransfection of rAAV-mIL-12 and a helper plasmid (pAAV/Ad) into 293 cells previously infected with adenovirus 5. After infection of D6 fibroblasts with rAAV-mIL-12, G418-resistant clones were isolated. Each of the 1D D6 clones isolated produced up to $5.2 \mathrm{ng} / 10^{6}$ cells/48 hours of mIL-12 as determined by enzyme-linked immunosorbent assay. Induction of interferon- $\gamma$, enhanced lymphocyte proliferation, and cytotoxicity assays confirmed biologically functional IL-12 production by the vector. This is the first report indicating that an rAAV vector expresses mIL-12, which can be used to model the effects of mlL-12 alone and/or in combination with other antitumor agents. Cancer Gene Therapy (2000) 7, 308-315

Key words: Adeno-associated virus; interleukin-12 vector; gene transfer.

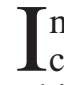
nterleukin-12 (IL-12) is a heterodimeric cytokine, consisting of p35 and p40 disulfide-linked subunits, $, 1,2$ which was initially shown to facilitate the generation of human cytotoxic $\mathrm{T}$ lymphocyte responses. ${ }^{3}$ Other activities of IL-12 include induction of interferon- $\gamma$ (IFN- $\gamma$ ) production from peripheral blood lymphocytes (PBLs), augmentation of the lytic activity of PBLs against various targets including neoplastic cells, and stimulation of PBL proliferation. ${ }^{4}$ It was shown subsequently that this cytokine could induce lymphocyte-activated killer cell activity from peripheral blood mononuclear cells, ${ }^{5}$ directly stimulate the production of IFN- $\gamma$ from peripheral blood $\mathrm{T}$ and natural killer (NK) cells, ${ }^{6}$ and enhance the lytic activity of NK cells.4,6 IL-12 or IL-12 signaling pathways have also been shown to play a critical role in directing $\mathrm{T}$ helper 1 type differentiation, ultimately resulting in cell-mediated immunity. ${ }^{7-10}$ The major sources of IL-12 include antigen-stimulated macrophages and B cells in peripheral blood mononuclear cells (reviewed in Ref. 11). In addition, IL-12 can also be produced

Received July 7, 1998; accepted April 24, 1999.

Address correspondence and reprint requests to Dr. Kenneth H. Cowan, Medicine Branch, National Cancer Institute, National Institutes of Health, 10/12N/226, Bethesda, MD 20892. by CD4 T cells, monocytes, dendritic cells, and neutrophils. ${ }^{12}$ Although human IL-12 is inactive in mice, mouse IL-12 (mIL-12) maintains full activity in human cells. ${ }^{13}$

In vivo, several investigators have shown that the systemic administration of recombinant IL-12 (rIL-12) leads to potent antitumor effects. ${ }^{14,15}$ IL-12 gene transfer studies employing plasmids, retrovirus, adenovirus, and vaccinia virus as well as nonviral gene transfer methods have similarly demonstrated significant tumor regressions, a decreased propensity for metastasis, and immunological memory in treated animals. ${ }^{15-36}$ The mechanism by which IL-12 exerts this antitumor effect is not known, but is likely to involve a combination of activities including the modulation of $\mathrm{T}$ cell populations, stimulation of IFN- $\gamma$ production, and inhibition of angiogenesis. ${ }^{37-41}$ A phase I gene therapy clinical trial employing a bicistronic retroviral vector expressing both human IL-12 subunits has been initiated in patients with metastatic cancer. ${ }^{42}$

Adeno-associated viruses (AAV) are single-stranded DNA parvoviruses that offer several advantages over other gene transfer vectors. For example, AAV are nonpathogenic in humans, display a broad host range of infectivity, and infect both dividing as well as quiescent cells. Moreover, recent reports indicate that high titers 
of recombinant AAV (rAAV) vectors can be readily generated (reviewed in Refs. 43-45). rAAV in vivo gene transfer studies have also demonstrated efficient longterm transduction and expression, in some cases continuing for $>1.5$ years. ${ }^{46}$ The $4.7-\mathrm{kb}$ AAV coding region ${ }^{47}$ is flanked by 145 -nucleotide inverted terminal repeat (ITR) sequences that are the minimum cis-acting elements required for viral replication, encapsidation, packaging, and rescue. ${ }^{48,49}$ AAV has a biphasic life cycle whereby coinfection with helper virus (such as adenovirus or Herpes virus) results in productive infection with viral replication (reviewed in Ref. 50). In the absence of helper virus, wild-type AAV enters a latent phase with site-specific integration into chromosome 19. Recently, an rAAV vector expressing human IL-12 has been reported. ${ }^{51}$ Because human IL-12 is nonfunctional in mice, this vector cannot be used to model the effects of the AAV vector-mediated expression of IL-12 in vivo against murine tumor models.

In this paper, we describe the construction of the first rAAV vector to express mIL-12 and further demonstrate that the IL-12 protein expressed by this vector is biologically functional as determined by the stimulation of IFN- $\gamma$ production from PBLs, enhanced lymphoblast proliferation, and enhanced cytotoxicity to a variety of tumor cell types.

\section{MATERIALS AND METHODS}

\section{Cell lines and plasmids}

Detroit 6 (D6) fibroblasts and 293 cells (human embryonic kidney cells) were maintained as described previously. ${ }^{52}$ K562 (human erythroleukemia) and Renca (mouse renal cell carcinoma) cells were maintained at $37^{\circ} \mathrm{C}, 5 \% \mathrm{CO}_{2}$ in RPMI 1640 media (Life Technologies, Gaithersburg, MD) supplemented with $10 \%$ fetal bovine serum and antibiotics $(50 \mu \mathrm{g} / \mathrm{mL}$ gentamicin, $100 \mu \mathrm{g} / \mathrm{mL}$ penicillin, and $2.5 \mu \mathrm{g} / \mathrm{mL}$ fungisone). The plasmids pAAV/Ad, ${ }^{52}$ pRep4, ${ }^{52}$ and $\mathrm{p} 008 \mathrm{Sub} / \mathrm{NeoR}^{53}$ have been described previously.

\section{Construction of rAAV-mIL-12 expression vector}

mIL-12 subunits and encephalomyocarditis virus internal ribosomal entry site (IRES) ${ }^{36}$ were first subcloned into an intermediate plasmid ( $\mathrm{pRep} 4$ ) before being ultimately subcloned into the AAV plasmid (p008Sub/Neo) to minimize manipulation and possible damage to the AAV ITRs. The p40 and p35 cDNAs were obtained from pBluescript $\mathrm{SK}^{+}$backbones kindly supplied by Dr. U. Gubler (Hoffman-La Roche, Nutley, NJ). The rAAV-mIL-12 plasmid was constructed by first subcloning the p35 cDNA into the plasmid pRep4, between the NotI and HindIII sites, yielding the plasmid pRep4/p35. Next, the p40 cDNA was subcloned into the plasmid pRep4/p35 between the BamHI and XhoI sites, yielding the plasmid pRep4/p35/p40. Primers were constructed to generate flanking $\mathrm{XhoI}$ sites on the IRES cDNA, ${ }^{36}$ which was then used as a template with a polymerase chain reaction amplification kit (PCR Master, Boehringer Mannheim, Indianapolis, Ind). The polymerase chain reaction product containing the IRES cDNA now flanked by $X h o$ I sites was subcloned into a TA cloning vector kit (Invitrogen, San Diego, Calif) to facilitate the selection of colonies. The IRES was then subcloned into the plasmid pRep4/p35/p40 between the XhoI site, yielding the plasmid mIL-12-pRep4. The Rous sarcoma virus (RSV)-driven mIL12-pRep4 expression cassette terminated by the polyadenylation signal of simian virus 40 (SV40) was then subjected to a partial SalI digest and subcloned into the compatible XhoI site of the AAV plasmid p008Sub/NeoR (driven by the thymidine kinase (TK) promoter) between the two AAV ITR sequences, yielding the final vector rAAV-mIL-12.

rAAV virions were generated ${ }^{54}$ by cotransfection $(60 \mu \mathrm{L}$ of lipofectamine (Life Technologies) as per the manufacturer's instructions) of the vector rAAV-mIL-12 $(10 \mu \mathrm{g})$ and the helper plasmid pAAV/Ad $(10 \mu \mathrm{g})$ into 293 cells infected 5 hours earlier by adenovirus 5 at a multiplicity of infection (MOI) of $10 . .^{53}$ After a 16 -hour incubation $\left(37^{\circ} \mathrm{C}, 5 \% \mathrm{CO}_{2}\right)$, the Opti-Mem I (Life Technologies) medium containing no supplements was replaced with RPMI 1640 medium supplemented with $2 \%$ fetal bovine serum and antibiotics. The 293 cells were harvested 72 hours later by scraping, centrifuged $(500 \times g, 5$ minutes $)$, resuspended in $20 \mathrm{ml}$ of phosphate buffered saline (PBS), and sonicated (three 20-second bursts, output control 5, duty cycle $50 \%$ ). The lysate was then heat-treated $\left(56^{\circ} \mathrm{C}\right.$ for 45 minutes $)$ to inactivate adenovirus and centrifuged $(500 \times g, 5$ minutes $)$ to remove cellular debris. ${ }^{52,54}$ Titers were performed on D6 cells incubated in the presence of $0.5 \mathrm{mg} / \mathrm{mL}$ of G418 (Geneticin, Life Technologies). Drug-resistant colonies were isolated at 10-14 days, and rAAV titers were calculated from the number of resistant colonies, averaging $1 \times 10^{4}$ infectious particles $/ \mathrm{mL}$. Similarly, D6 cells stably transfected with rAAV-mIL-12 at an MOI of 0.001 (1 viral particle/1000 D6 cells) were isolated by incubation in G418 $(0.5 \mathrm{mg} / \mathrm{mL})$. NeoR colonies were harvested and expanded, and aliquots of supernatant/medium from these clones were assayed for mIL-12 activity.

\section{mIL-12 ELISA}

Aliquots of supernatants from D6 rAAV-mIL-12 stably transfected clones were assayed in duplicate for activity using a mIL-12 enzyme-linked immunosorbent assay (ELISA) kit (Biosource International, Camarillo, Calif) as per the manufacturer's recommendations. The assay recognizes both natural mIL-12 and rmIL-12 as well as the free p40 subunit and has a minimum detectable dose of $<2 \mathrm{pg} / \mathrm{mL}$. Activity was expressed as ng/ $10^{6}$ cells/48 hours. The D6 rAAV-mIL-12 clone shown to be producing the most significant quantities of mIL-12 by ELISA of supernatants was used in various IL-12 biological assays.

\section{Isolation of PBLs and phytohemagglutinin (PHA)- activated blasts}

Healthy donor human PBLs were isolated on Lymphoprep (Nycomed Lymphoprep, Life Technologies) as per the manufacturer's instructions and activated by incubation with 2 $\mu \mathrm{g} / \mathrm{mL}$ PHA (Difco, Detroit, MI) for 72 hours $^{1}$ in RPMI 1640 medium containing $10 \%$ AB serum with antibiotics. Lymphoblasts were washed with fresh medium, and $5 \times 10^{5}$ cells were incubated with various amounts of supernatant from D6 rAAV-mIL-12 clone 3 or control rmIL-12 (Biosource International). After a 48 -hour incubation at $37^{\circ} \mathrm{C}$ in $5 \% \mathrm{CO}_{2}$, the 96-well plates were centrifuged $(500 \times g, 5$ minutes $)$, and the supernatants were assayed in duplicate by ELISA for IFN- $\gamma$ production as per the manufacturer's instructions. Anti-- 


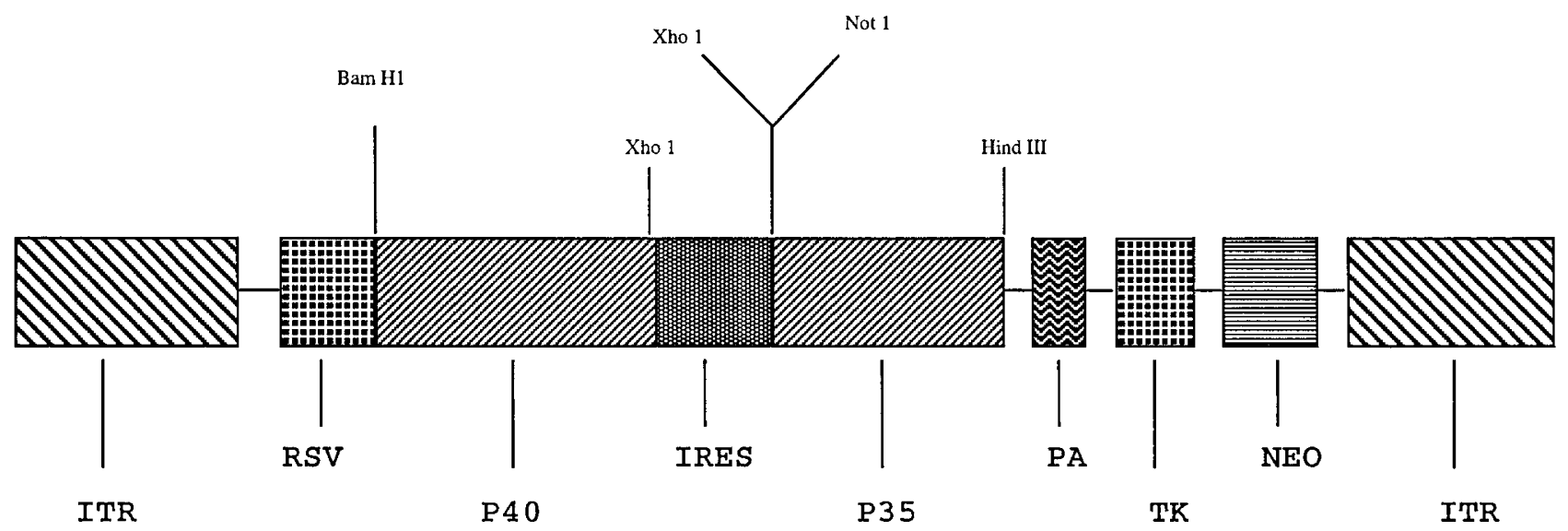

Figure 1. Bicistronic rAAV-expressing mlL-12 (rAAV-mlL-12). Restriction sites are as indicated. Details of the cloning steps and virus production are provided in Materials and Methods. The total size of the expression cassette inserted between the AAV ITRs is $4.9 \mathrm{~kb}$. RSV, RSV promoter; p40, subunit of mIL-12; p35, subunit of mIL-12; PA, SV40 polyadenylation sequence; TK, TK promoter; Neo, neomycin-resistance gene; ITR, ITR sequences of AAV.

mIL-12 antibody (Ab) (Biosource International) was added to reactions as indicated.

\section{$\left.{ }^{3} \mathrm{H}\right]$ thymidine proliferation}

PHA-activated peripheral blood lymphoblasts $\left(5 \times 10^{5}\right.$ cells $)$ prepared as described above were incubated at $37^{\circ} \mathrm{C}$ for 48 hours in $5 \% \mathrm{CO}_{2}$ in triplicate in 96-well, U-bottom culture plates with increasing amounts of supernatant from D6 rAAVmIL-12 clone 3 or control rmIL-12. Ab to mIL-12 $(10 \mu \mathrm{g} / \mathrm{mL})$ was also added as indicated. Each well (200 $\mu \mathrm{L}$ final volume) was pulsed with $1 \mu \mathrm{Ci}$ of $\left[{ }^{3} \mathrm{H}\right]$ thymidine for 16 hours, and $\left[{ }^{3} \mathrm{H}\right]$ thymidine uptake was determined by standard liquid scintillation counting. 55

\section{Cytotoxicity}

Healthy donor human PBLs were isolated using Lymphoprep as described above and monocyte-depleted by plastic adherence. These effector cells $\left(5 \times 10^{5}\right)$ were then incubated with either concentrated (Centricon-SR3 centrifugal concentrator, Amicon, Beverly, Mass) D6 rAAV-mIL-12 clone 3 supernatant (containing $47 \mathrm{ng}$ of IL-12) or with control rmIL-12 (0.5 ng) for 48 hours. The K562 (human erythroleukemia) cell line and Renca (murine renal carcinoma) cell line were used as target cells. Effector cells and target cells were incubated at $37^{\circ} \mathrm{C}$ for 16 hours at the following effector to target (E:T) ratios: 100:1, 50:1, 25:1, 6.25:1, 3.125:1, 1.56:1, and 0.78:1. Cytotoxicity was determined by lactate dehydrogenase $(\mathrm{LDH})$ release using a colorimetric (absorbance at $490 \mathrm{~nm}$ ), non-radioactive cytotoxicity assay kit (CytoTox 96, Promega, Madison, Wis). To calculate cytotoxicity (as per the manufacturer's instructions), the average of the absorbance values of the background control (culture medium containing no cells) was first subtracted from the experimental samples, from the target cells incubated alone (target cell spontaneous LDH release), and from the absorbance value of the effector cell spontaneous LDH release from PBLs. Next, the average of the absorbance values of the background medium control was subtracted from the absorbance values obtained for the target cell maximum $\mathrm{LDH}$ release control, which was determined by lysing target cells with $\mathrm{NaOH}$; the percentage of cytotoxicity was calculated using the following formula:

$\%$ Cytotoxicity $=($ experimental - effector spontaneous -

target spontaneous/target maximum -

target spontaneous) $\times 100$.

All samples were tested in triplicate or quadruplicate.

\section{RESULTS}

\section{rAAV-mIL-12 vector construction}

The various components of the mIL-12 expression cassette were first subcloned into the plasmid pRep4 to avoid excessive manipulation and possible damage to the AAV ITRs of the plasmid p008Sub/Neo. The mIL-12 expression cassette in pRep4 was then partially digested with SalI and subcloned into the 008Sub/Neo plasmid between the two AAV ITRs, yielding the final rAAVmIL-12 vector. The final rAAV-mIL-12 bicistronic vector $(4.9 \mathrm{~kb})$ (Fig 1) is composed of the p40 $(1.0-\mathrm{kb})$ subunit, the p35 (697-bp) subunit, and the IRES (674 bp) driven by the RSV promoter (623 bp) and terminated by the polyadenylation signal $(370 \mathrm{bp})$ of SV40. (The RSV promoter and polyadenylation signal originate from pRep4.) The vector also contains a NeoR gene driven by the TK promotor (TK/NeoR, $1.1 \mathrm{~kb}$ ), which is contained in the plasmid p008Sub/NeoR.

Following lipofectamine cotransfection of the plasmid rAAV-mIL-12 and the helper plasmid pAAV/Ad into 293 cells previously infected with adenovirus 5, cells were harvested and rAAV virions were generated as described in Materials and Methods. To assess the functional expression of mIL-12 by rAAV-mIL-12, D6 cells were infected with the vector and G418-resistant clones 


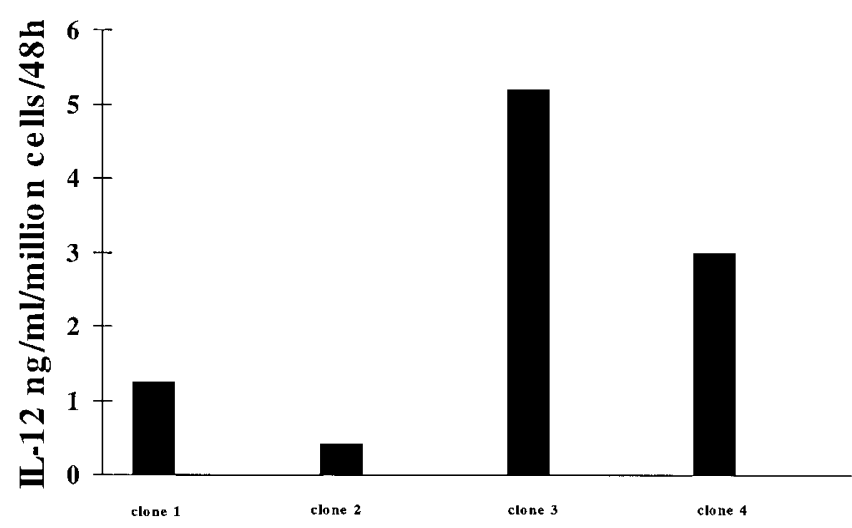

Figure 2. IL-12 production from rAAV-mIL-12 D6 clones. D6 cells were infected with the rAAV-mIL-12 vector $\left(10^{4}\right.$ titer) at a low $\mathrm{MOI}$ of 0.001 ( 1 viral particle/1000 D6 cells) to facilitate harvesting individual clones. Clones were selected in G418 (neomycin), and supernatants were screened for mIL-12 activity as determined in duplicate by ELISA. Of the $10 \mathrm{mIL}-12$-producing clones isolated, the $\mathrm{mlL}-12$ activity in the supernatant from the clones producing the highest quantity of IL-12 (5.2 ng/10 cells/48 hours) is shown.

were isolated. Aliquots of supernatant from 10 G418resistant D6 clones were screened for mIL-12 production using an ELISA that detects both natural mIL-12 and rmIL-12 as well as the free p40 subunit. All 10 NeoR clones were found to express mIL-12. The results of the mIL-12 assay for the four NeoR D6 clones with the highest levels of mIL-12 expression are shown in Figure 2. Clone 3 (D6 rAAV-mIL-12 clone 3) was found to produce $\sim 5.2 \mathrm{ng}$ of $\mathrm{mIL}-12 / 10^{6}$ cells/48 hours. Supernatant from nontransfected D6 cells produced no detectable mIL-12 by ELISA (data not shown). Aliquots of supernatant from D6 rAAV-mIL-12 clone 3 produced the greatest amount of IL-12 and were used in all subsequent experiments designed to investigate the biologic characteristics of the rAAV-mIL-12 vector product. mIL-12 expression from this clone has been stable for $>9$ months in culture.

\section{Enhanced IFN- $\gamma$ production from PHA-activated blasts}

To verify that the mIL-12 being produced from D6 rAAV-mIL-12 clone 3 was biologically active, several functional IL-12 assays were performed. The production of IFN- $\gamma$ from PHA-stimulated human lymphoblasts exposed to various amounts of aliquots of supernatant from the D6 rAAV-mIL-12 clone 3 is shown in Figure 3. PHA-activated blasts produced a baseline $300 \mathrm{pg} / \mathrm{mL} /$ $5 \times 10^{5}$ cells $/ 36$ hours of IFN- $\gamma$. Incubating PHA blasts with supernatant from the D6 rAAV-mIL-12 clone 3 (containing $20 \mathrm{pg}, 50 \mathrm{pg}$, and $100 \mathrm{pg}$ of mIL-12 as determined by ELISA) resulted in increasing amounts of IFN- $\gamma$ production in a dose-dependent manner. PHAactivated blasts incubated with aliquots of supernatant from D6 rAAV-mIL-12 clone 3 (containing $100 \mathrm{pg}$ of mIL-12 as determined by ELISA assay) resulted in the production of $>500 \mathrm{pg}$ of IFN- $\gamma / \mathrm{ml} / 5 \times 10^{5}$ cells $/ 36$ hours. Furthermore, the addition of mIL-12 Ab to PHA-activated blasts incubated with supernatant from D6 rAAV-mIL-12 clone 3 (containing 50 pg of IL-12) suppressed the IFN- $\gamma$ production back down to baseline, demonstrating the specificity of this enhancement for IL-12. IFN- $\gamma$ production following the addition of control rmIL-12 in the presence and absence of $\mathrm{Ab}$ is also shown as a positive control.

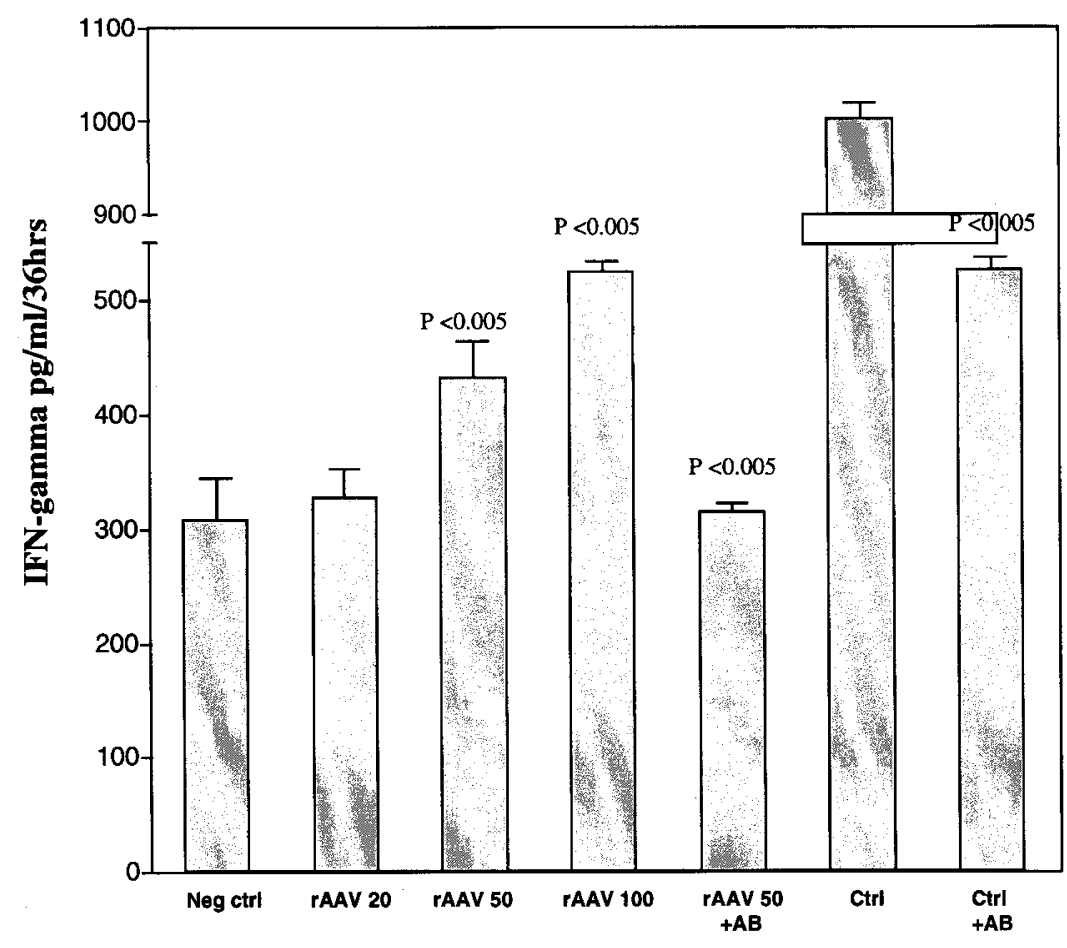

Figure 3. Dose-dependent enhanced secretion of IFN- $\gamma$ from PHA-activated lymphoblasts incubated with rAAV-mlL-12. PHA-activated lymphoblasts were incubated with supernatant from D6 rAAVmlL-12 clone $3(20,50$, and 100 pg of IL-12) for 36 hours. IFN- $\gamma$ production was determined in duplicate from the supernatants by ELISA. Where indicated, $\mathrm{Ab}(\mathrm{AB})$ to $\mathrm{mlL}-12$ was also added to a final concentration of $10 \mu \mathrm{g} / \mathrm{mL}$. Control (Ctrl) rlL-12 (500 pg) with and without $\mathrm{Ab}$ is also shown. 
Figure 4. Enhanced proliferation of PHA-activated lymphoblasts by rAAV-mIL-12. PHA-activated lymphoblasts were incubated for 48 hours with supernatant from D6 rAAV-mIL-12 clone 3 equivalent to 32 pg of IL-12 or $500 \mathrm{pg}$ of control (Ctrl) rlL-12 and then pulsed for 16 hours with $1 \mu \mathrm{Ci}$ of $\left[{ }^{3} \mathrm{H}\right]$ thymidine. $\mathrm{mlL}-12 \mathrm{Ab}(10 \mu \mathrm{g} / \mathrm{mL})$ was added to incubation mixtures as indicated.

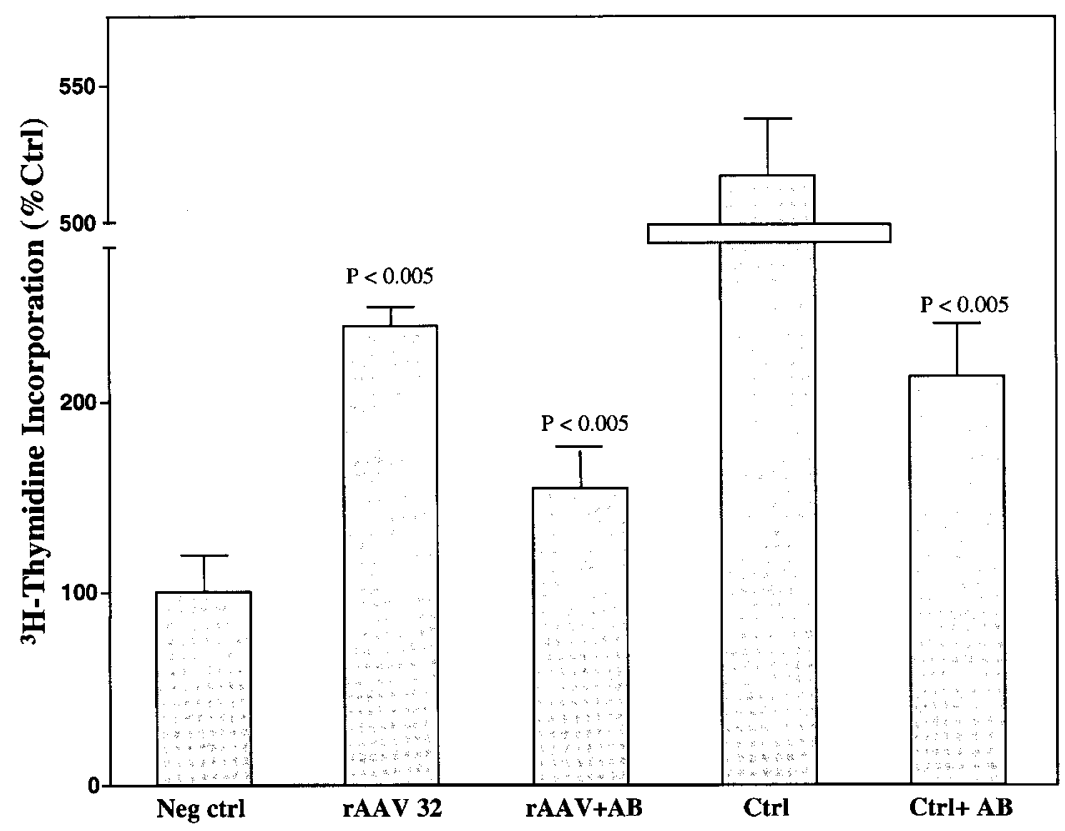

\section{Enhanced proliferation of PHA-activated blasts}

The ability of supernatant from the D6 rAAV-mIL-12 clone 3 to enhance PHA-activated lymphoblast proliferation was also examined. Human PHA-stimulated blasts were incubated for 48 hours with either aliquots of supernatant from D6 rAAV-mIL-12 clone 3, control rmIL-12, or no IL-12. Cells were then pulsed for 16 hours with $\left[{ }^{3} \mathrm{H}\right]$ thymidine, and the radiolabel incorporation into cells was determined as described in Materials and Methods. As shown in Figure 4, $\left[{ }^{3} \mathrm{H}\right]$ thymidine incorporation into lymphoblasts increased by $239 \%$ following incubation with as little as $32 \mathrm{pg}$ of rAAV-mIL-12 isolated from the supernatant of D6 rAAV-mIL-12 clone 3. Furthermore, this enhancement was suppressed by the addition of $\mathrm{Ab}$ to $\mathrm{mIL}-12$, demonstrating that the increased PBL proliferation was due specifically to the activity of IL-12.

\section{Stimulation of NK cell activity of PBLS}

The ability of supernatant from D6 rAAV-mIL-12 clone 3 to enhance the NK cell-mediated cytotoxicity of K562 and Renca tumor cell lines was also investigated. Monocyte-depleted PBLs were incubated with concentrated supernatant from the D6 rAAV-mIL-12 clone 3 or with control rIL-12. These effector PBLs were then incubated with various target tumor cells at a number of different E:T cell ratios with appropriate controls. After 16 hours, a non-radioactive cytotoxicity assay (which measures LDH release) was performed and absorbance at $490 \mathrm{~nm}$ was measured. From these values the percentage cytotoxicity was calculated as described in Materials and Methods. The percentage of cytotoxicity at an E:T ratio of 25:1 for all samples is shown in Figure 5. Incubation of PBLs with $\sim 50$ ng of IL-12 produced by D6 rAAVmIL-12 clone 3 produced a cytotoxicity of $22 \%$ against
Renca (murine renal cell carcinoma) cells and 23\% against K562 (human erythroleukemia) cells, respectively, above background. Cytotoxicity resulting from incubation with rmIL-12 is also shown as a positive control.

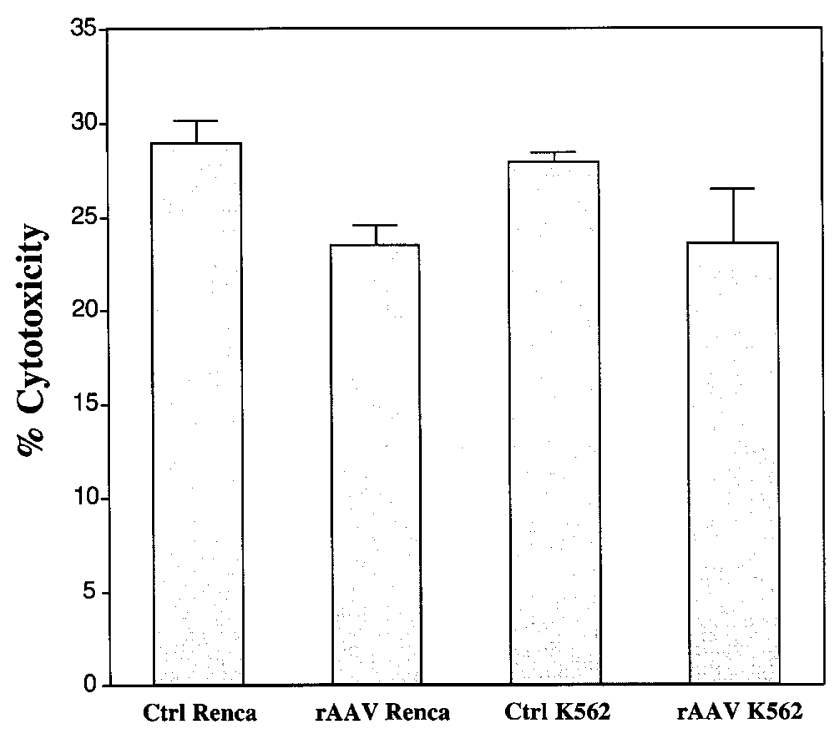

Figure 5. Enhanced NK cell killing by rAAV-mIL-12. PBLs depleted of monocytes by plastic adherence were incubated with either concentrated supernatant from the D6 rAAV-mIL-12 clone $(47 \mathrm{ng})$ or control (Ctrl) mlL-12 (500 pg) for 48 hours. Effector PBLs were then incubated with tumor target cells at various $\mathrm{E}: \mathrm{T}$ ratios and assayed in triplicate or quadruplicate using a colorimetric cytotoxicity assay that quantitatively measures $\mathrm{LDH}$ release upon cell lysis. The E:T ratio shown for all samples was $25: 1$, and cytotoxicity was calculated as described in Materials and Methods. 


\section{DISCUSSION}

Both systemic administration of IL-1214,15,35 and intratumoral gene transfer of IL-12 via retroviral ${ }^{17}$ and adenoviral vectors ${ }^{18}$ have been shown to suppress tumor growth and decrease the propensity for tumor metastasis in mice. In addition, in animals attaining a complete response to this therapy, immunological memory has been observed in that reinoculation with neoplastic cells failed to produce tumors in these animals. In clinical studies, the toxicity associated with intratumoral viral gene transfer of human IL-1256 is proving to be less toxic than the toxicity reported with systemic administration of human rIL-12.57 AAV vectors have several potential advantages over retroviral and adenoviral gene transfer vectors and recently, an rAAV vector expressing a human IL-12 fusion protein has been reported and characterized. 51 At 48 hours following infection of human acute myelocytic leukemia blasts with this vector, which did not contain a selectable marker, 2-6 ng of biologically functional human IL- $12 / \mathrm{mL} / 10^{6}$ cells $/ 48$ hours was produced. Unlike mIL-12 which maintains activity on both mouse and human lymphocytes, human IL-12 is biologically inactive on murine cells. ${ }^{13}$ Thus, the antitumor effects of an AAV vector expressing human IL-12 cannot readily be studied in murine tumor models. To facilitate rAAV IL-12 studies in mice, we have constructed the first rAAV vector that expresses mIL-12.

To characterize the biological function of the rAAVmIL-12 vector, D6 fibroblasts were infected with a low titer virus, clones were selected in G418, and supernatant from stably transfected clones was assayed for secreted mIL-12 by ELISA. Supernatant from the clone (D6 rAAV-mIL-12 clone 3) secreting the greatest amount of IL-12 was used in three assays, each of which measures the biological activity of IL-12. We show that supernatant from the stably transfected D6 rAAVmIL-12 clone 3 was able to enhance, in a dose-dependent manner, the IFN- $\gamma$ production from PHA-activated blasts, and that this enhancement could be blocked specifically by the addition of mIL-12 Ab. Supernatant from this clone also mediated enhanced proliferation of PHA-activated blasts, an activity that was also suppressed by the addition of mIL-12 Ab. Lastly, we demonstrate the ability of supernatant from the D6 rAAVmIL-12 clone to stimulate the NK cell-mediated cytotoxicity of tumor cell lines.

The development of an rAAV vector that expresses mIL-12 makes it feasible to investigate the effects of AAV-IL-12 gene transfer alone and in combination with other antineoplastic agents in a variety of murine tumor models. In addition, retroviral, ${ }^{17}$ adenoviral, ${ }^{58}$ and AAV mIL-12 expression vectors can now be compared with respect to transduction efficiency, length of transgene expression, and efficacy of antitumor response. We have now generated a high titer $\left(10^{12} / \mathrm{mL}\right)$ rAAV-mIL-12 preparation from this vector that can be used for in vivo murine tumor growth inhibition studies. In this regard, we examined the effectiveness of rAAV-IL-12 to inhibit the growth of Renca tumors in vivo and compared the activity of rAAV-IL-12 with Adwtp53, which has been reported to inhibit the growth of these tumors in vivo. ${ }^{59}$ $\mathrm{BALB} / \mathrm{c}$ mice were injected subcutaneously with Renca cells $\left(2 \times 10^{5}\right)$; next, following the formation of palpable tumors (7-10 days), control rAAV-Lac, rAAV-IL-12 $\left(1 \times 10^{8}\right.$ virus/day $\left.\times 6\right)$, or Adwtp53 $\left(1 \times 10^{8}\right.$ plaqueforming units/day $\times 6$ ) was injected directly into tumors. Growth of the tumors was measured for the next 3-4 weeks, and the tumor volume was calculated using the following formula: length $\times$ width $\times$ thickness $\times \mathrm{p} / 6$, as described previously. ${ }^{59}$ Our preliminary results show that $\mathrm{rAAV}-\mathrm{IL}-12$ reduced the growth of Renca tumors by $60 \%$ compared with the untreated controls (tumor volume $80 \pm 15 \mathrm{~mm}^{2}$ for the untreated controls compared with $30 \pm 6 \mathrm{~mm}^{2}$ at day 28 for rAAV-IL-12treated tumors). Treatment with control rAAV-Lac, under these conditions, was only slightly effective and reduced tumor growth by $30 \%$ (tumor volume $55 \pm 5$ $\mathrm{mm}^{2}$ ). In contrast, Adwtp53 was significantly more effective $\left(80 \pm 15 \mathrm{~mm}^{2}\right.$ for controls compared with $12 \pm 3$ $\mathrm{mm}^{2}$ for Adwtp53) as previously noted for Renca tumors. Although a limited number of animals were used in this study, these preliminary results nevertheless are encouraging and suggest that rAAV-IL-12 alone and/or in combination with other anticancer drugs might be beneficial for the treatment of certain cancers. Work is in progress to further evaluate the effectiveness of rAAV-IL-12 (and in combination with drugs) to inhibit various tumors in in vivo models.

\section{REFERENCES}

1. Stern AS, Podlaski FJ, Hulmes JD, et al. Purification to homogeneity and partial characterization of cytotoxic lymphocyte maturation factor from human B-lymphoblastoid cells. Proc Natl Acad Sci USA. 1990;87:6808-6812.

2. Podlaski FJ, Nanduri VB, Hulmes JD, et al. Molecular characterization of interleukin 12. Arch Biochem Biophys. 1992;294:230-237.

3. Gately MK, Wilson DE, Wong HL. Synergy between recombinant IL-2 and IL-2-depleted lymphokine-containing supernatants in facilitating allogeneic human cytolytic T lymphocyte responses in vitro. J Immunol. 1986;136; 1274-1282.

4. Kobayashi M, Fitz L, Ryan M, et al. Identification and purification of natural killer cell stimulatory factor (NKSF), a cytokine with multiple biologic effects on human lymphocytes. J Exp Med. 1989;170:827-845.

5. Wong HL, Wilson DE, Jenson JC, Familletti PC, Stremlo DL, Gately MK. Characterization of a factor(s) which synergizes with recombinant interleukin 2 in promoting allogeneic human cytolytic T-lymphocyte responses in vitro. Cell Immunol. 1988;111:39-54.

6. Naume B, Gately M, Espevik T. A comparative study of IL-12 (cytotoxic lymphocyte maturation factor)-, IL-2-, and IL-7-induced effects on immunomagnetically purified CD56 $^{+}$NK cells. J Immunol. 1992;148:2429-2436.

7. Kiniwa M, Gately M, Gubler U, Chizzonite R, Fargeas C, Delespesse G. Recombinant interleukin-12 suppresses the synthesis of immunoglobulin E by interleukin-4-stimulated human lymphocytes. J Clin Invest. 1992;90:262-266.

8. Manetti R, Parronchi P, Giudizi MG, et al. Natural killer 
cell stimulatory factor (interleukin 12 (IL-12)) induces T helper type 1 (Th1)-specific immune responses and inhibits the development of IL-4-producing Th cells. $J$ Exp Med. 1993;177:1199-1204.

9. Hsieh CS, Macatonia SE, Tripp CS, Wolf SF, O’Garra A, Murphy KM. Development of TH1 CD4 ${ }^{+} \mathrm{T}$ cells through IL-12 produced by Listeria-induced macrophages. Science. 1993;260:547-549.

10. Kaplan MH, Sun YL, Hoey T, Grusby MJ. Impaired IL-12 responses and enhanced development of Th2 cells in Stat4-deficient mice. Nature. 1996;382:174-177.

11. Tahara H, Lotze MT. Antitumor effects of interleukin-12 (IL-12): applications for the immunotherapy and gene therapy of cancer. Gene Ther. 1995;2:96-106.

12. Lucey DR, Clerici M, Shearer GM. Type 1 and type 2 cytokine dysregulation in human infectious, neoplastic, and inflammatory diseases. Clin Microbiol Rev. 1996;9:532562.

13. Schoenhaut DS, Chua AO, Wolitzky AG, et al. Cloning and expression of murine IL-12. J Immunol. 1992;148: 3433-3444.

14. Brunda MJ, Luistro L, Warrier RR, et al. Antitumor and antimetastatic activity of interleukin 12 against murine tumors. J Exp Med. 1993;178:1223-1230.

15. Nastala CL, Edington HD, McKinney TG, et al. Recombinant IL-12 administration induces tumor regression in association with IFN- $\gamma$ production. J Immunol. 1994;153: 1697-1706.

16. Zitvogel L, Tahara H, Cai Q, et al. Construction and characterization of retroviral vectors expressing biologically active human interleukin-12. Hum Gene Ther. 1994; 5:1493-1506.

17. Tahara H, Zeh HR, Storkus WJ, et al. Fibroblasts genetically engineered to secrete interleukin 12 can suppress tumor growth and induce antitumor immunity to a murine melanoma in vivo. Cancer Res. 1994;54:182-189.

18. Bramson JL, Hitt M, Addison CL, Muller WJ, Gauldie J, Graham FL. Direct intratumoral injection of an adenovirus expressing interleukin-12 induces regression and longlasting immunity that is associated with highly localized expression of interleukin-12. Hum Gene Ther. 1996;7: 1995-2002.

19. Meko JB, Yim JH, Tsung K, Norton JA. High cytokine production and effective antitumor activity of a recombinant vaccinia virus encoding murine interleukin 12 . Cancer Res. 1995;55:4765-4770.

20. Tahara H, Zitvogel L, Storkus WJ, et al. Effective eradication of established murine tumors with IL-12 gene therapy using a polycistronic retroviral vector. J Immunol. 1995;154:6466-6474.

21. Martinotti A, Stoppacciaro A, Vagliani M, et al. CD4 T cells inhibit in vivo the CD8-mediated immune response against murine colon carcinoma cells transduced with interleukin-12 genes. Eur J Immunol. 1995;25:137-146.

22. Obana S, Miyazawa H, Hara E, et al. Induction of anti-tumor immunity by mouse tumor cells transfected with mouse interleukin-12 gene. Jpn J Med Sci Biol. 1995;48:221-236.

23. Zitvogel L, Couderc B, Mayordomo JI, Robbins PD, Lotze MT, Storkus WJ. IL-12-engineered dendritic cells serve as effective tumor vaccine adjuvants in vivo. Ann NY Acad Sci. 1996;795:284-293.

24. Rakhmilevich AL, Turner J, Ford MJ, et al. Gene gunmediated skin transfection with interleukin 12 gene results in regression of established primary and metastatic murine tumors. Proc Natl Acad Sci USA. 1996;93:6291-6296.
25. Nishimura T, Watanabe K, Yahata T, et al. Application of interleukin 12 to antitumor cytokine and gene therapy. Cancer Chemother Pharmacol. 1996;38:S27-S34.

26. Caruso M, Pham-Nguyen K, Kwong YL, et al. Adenovirusmediated interleukin-12 gene therapy for metastatic colon carcinoma. Proc Natl Acad Sci USA. 1996;93:11302-11306.

27. Rakhmilevich AL, Janssen K, Turner J, Culp J, Yang NS. Cytokine gene therapy of cancer using gene gun technology: superior antitumor activity of interleukin-12. Hum Gene Ther. 1997;8:1303-1311.

28. Chen L, Chen D, Block E, O’Donnell M, Kufe DW, Clinton SK. Eradication of murine bladder carcinoma by intratumor injection of a bicistronic adenoviral vector carrying cDNAs for the IL-12 heterodimer and its inhibition by the IL-12 p40 subunit homodimer. J Immunol. 1997;159:351-359.

29. Schmitt M, Ikeda H, Nagata $Y$, et al. Involvement of Tcell subsets and natural killer (NK) cells in the growth suppression of murine fibrosarcoma cells transfected with interleukin-12 (IL-12) genes. Int J Cancer. 1997;72:505511.

30. Lieu FH, Hawley TS, Fong AZ, Hawley RG. Transmissibility of murine stem cell virus-based retroviral vectors carrying both interleukin-12 cDNAs and a third gene: implications for immune gene therapy. Cancer Gene Ther. 1997;4:167-175.

31. Lieschke GJ, Rao PK, Gately MK, Mulligan RC. Bioactive murine and human interleukin-12 fusion proteins which retain antitumor activity in vivo. Nat Biotechnol. 1997;15: 35-40.

32. Myers JN, Mank-Seymour A, Zitvogel L, et al. Interleukin-12 gene therapy prevents establishment of SCC VII squamous cell carcinomas, inhibits tumor growth, and elicits long-term antitumor immunity in syngeneic $\mathrm{C} 3 \mathrm{H}$ mice. Laryngoscope. 1998;108:261-268.

33. Lee YL, Tao MH, Chow YH, Chiang BL. Construction of vectors expressing bioactive heterodimeric and singlechain murine interleukin-12 for gene therapy. Hum Gene Ther. 1998;9:457-465.

34. Lode HN, Dreier T, Xiang R, Varki NM, Kang AS, Reisfeld RA. Gene therapy with a single chain interleukin 12 fusion protein induces $\mathrm{T}$ cell-dependent protective immunity in a syngeneic model of murine neuroblastoma. Proc Natl Acad Sci USA. 1998;95:2475-2480.

35. $\mathrm{Mu} \mathrm{J}$, Zou JP, Yamamoto $\mathrm{N}$, et al. Administration of recombinant interleukin 12 prevents outgrowth of tumor cells metastasizing spontaneously to lung and lymph nodes. Cancer Res. 1995;55:4404-4408.

36. Hoshino T, Jiang YZ, Dunn D, et al. Transfection of interleukin-12 cDNAs into tumor cells induces cytotoxic immune responses against native tumor: implications for tumor vaccination. Cancer Gene Ther. 1998;5:150-157.

37. Fujiwara H, Clark SC, Hamaoka T. Cellular and molecular mechanisms underlying IL-12-induced tumor regression. Ann NY Acad Sci. 1996;795:294-309.

38. Majewski S, Marczak M, Szmurlo A, Jablonska S, Bollag W. Interleukin-12 inhibits angiogenesis induced by human tumor cell lines in vivo. J Invest Dermatol. 1996;106:11141118.

39. Sgadari C, Angiolillo AL, Tosato G. Inhibition of angiogenesis by interleukin-12 is mediated by the interferoninducible protein 10. Blood. 1996;87:3877-3882.

40. Voest EE, Kenyon BM, O'Reilly MS, Truitt G, D'Amato RJ, Folkman J. Inhibition of angiogenesis in vivo by interleukin 12. J Natl Cancer Inst. 1995;87:581-586.

41. Shurin MR, Esche C, Peron JM, Lotze MT. Antitumor 
activities of IL-12 and mechanisms of action. Chem Immunol. 1997;68:153-174.

42. Tahara H, Lotze MT, Robbins PD, Storkus WJ, Zitvogel L. IL-12 gene therapy using direct injection of tumors with genetically engineered autologous fibroblasts. Hum Gene Ther. 1995;6:1607-1624.

43. Xiao X, Li J, McCown TJ, Samulski RJ. Gene transfer by adeno-associated virus vectors into the central nervous system. Exp Neurol. 1997;144:113-124.

44. Xiao X, Li J, Samulski RJ. Production of high-titer recombinant adeno-associated virus vectors in the absence of helper adenovirus. J Virol. 1998;72:2224-2232.

45. Chatterjee S, Wong K Jr. Adeno-associated virus vectors for gene therapy of the hematopoietic system. Curr Top Microbiol Immunol. 1996;218:61-73.

46. Xiao X, Li J, Samulski RJ. Efficient long-term gene transfer into muscle tissue of immunocompetent mice by adeno-associated virus vector. J Virol. 1996;70:8098-8108.

47. Srivastava A, Lusby EW, Berns KI. Nucleotide sequence and organization of the adeno-associated virus 2 genome. J Virol. 1983;45:555-564.

48. Wang XS, Ponnazhagan S, Srivastava A. Rescue and replication signals of the adeno-associated virus 2 genome. J Mol Biol. 1995;250:573-580.

49. Wang XS, Ponnazhagan S, Srivastava A. Rescue and replication of adeno-associated virus type 2 as well as vector DNA sequences from recombinant plasmids containing deletions in the viral inverted terminal repeats: selective encapsidation of viral genomes in progeny virions. J Virol. 1996;70:1668-1677.

50. Berns KI, Giraud C. Biology of adeno-associated virus. Curr Top Microbiol Immunol. 1996;218:1-23.

51. Anderson R, Macdonald I, Corbett T, Hacking G, Lowdell
MW, Prentice HG. Construction and biological characterization of an interleukin-12 fusion protein (Flexi-12): delivery to acute myeloid leukemic blasts using adenoassociated virus. Hum Gene Ther. 1997;8:1125-1135.

52. Walsh CE, Nienhuis AW, Samulski RJ, et al. Phenotypic correction of Fanconi anemia in human hematopoietic cells with a recombinant adeno-associated virus vector. J Clin Invest. 1994;94:1440-1448.

53. Qazilbash MH, Xiao X, Seth P, Cowan KH, Walsh CE. Cancer gene therapy using a novel adeno-associated virus vector expressing human wild-type p53. Gene Ther. 1997; $4: 675-682$.

54. Rolling F, Samulski RJ. AAV as a viral vector for human gene therapy: generation of recombinant virus. Mol Biotechnol. 1995;3:9-15.

55. Xu H, Rizzo LV, Caspi RR. IL-12 induces growth of the IL-4-dependent CT4S line and has a synergistic effect on IL-4-induced CT4S proliferation. J Immunol Methods. 1995; 181:245-251.

56. Lotze MT, Zitvogel L, Campbell R, et al. Cytokine gene therapy of cancer using interleukin-12: murine and clinical trials. Ann NY Acad Sci. 1996;795:440-454.

57. Lamont AG, Adorini L. IL-12: a key cytokine in immune regulation. Immunol Today. 1996;17:214-217.

58. Bramson J, Hitt M, Gallichan WS, Rosenthal KL, Gauldie J, Graham FL. Construction of a double recombinant adenovirus vector expressing a heterodimeric cytokine: in vitro and in vivo production of biologically active interleukin-12. Hum Gene Ther. 1996;7:333-342.

59. Li Z, Rakar A, Katayose Y, et al. Efficacy of multiple administration of a recombinant adenovirus expressing wild-type p53 in an immune-competent mouse tumor model. Gene Ther. 1998;5:605-613. 